\title{
STRESS MANAGEMENT TECHNIQUES RECOMMENDED FOR STUDENTS
}

Annotation: This article deals with the brain-based education which includes problem solving materials and type of yoga exercises for students as well as for teachers. Stress is a survival programme and has some negative effects on learning. The focus in the context is based on different stress management techniques. To cope with stress there are recommended some types of yoga exercises. An intensive focus should be put on physical exercise: it contains positive impacts not only on health, but also on cognitive learning.

Keywords: stress, anxiety, students, yoga, meditation, breathing and endorphin.

Introduction. Stress is a situation, which evokes negative thoughts and feelings in a person, but not all people feel this situation stressful or they do not experience the same negative thoughts and feelings when you feel stressed.

A critical issue that is concerned to stress among students is its effect on learning. The Yerkes-Dodson law (1908) postulates that individuals under the low and high level of stress learn the least and that those under moderate stress learn the most. A field study and laboratory tests support the notion that the excessive stress is harmful to students' performance [1]. For example: it might effect on concentration on a lesson.

The education in Kazakhstan is a very important turning point in the academic life of students for a further career move. Stress is a pressure, worry, strain or tension resulting from mental or social, physical, or emotional distress, difficult circumstances etc. Stress, which has effect on students, can be categorized as academic, financial, time or health related and their selfimposed. All these brew up a perfect storm of stress in their minds and create an inability to meet them [2].

Students react to stress in a variety of ways. For some students, the time of college is stressful because it is different from the time of the high school. For others, separation from home is a source of stress and for some students tuition fee leads to the stress because they have to work in a part-time jobs in order to cover all the all these important expenses. Although some some kind of a stress is necessary for personal growth to occur, the amount of stress can overwhelm a student and affect the ability to cope.

It is true that the high aspirations and negative attitudes lead to the mental disorder, depression, stress and even suicide among the students [2]. Researchers of the company "Project Laboratory" found out that most of the residents of Kazakhstan experience stress, and only one third of residents consider their way of life in the health way, reports NUR.KZ. 310 citizens of Kazakhstan between 18 and 60 years old took part in the survey. More than half of respondents complain that they often or constantly experience stress [3]. As our research shows, the stress is a big problem not only in Kazakhstan, but also in other countries. For instance, one in four North Americans will suffer from an anxiety disorder at some point in their life [4].

Problem solving materials and methods. There are a variety of techniques that can help relieve symptoms of stress. Yoga is a great way to reduce anxiety and stress. Here is how yoga can help you reduce stress and shown 5 ways of yoga which lower stress and anxiety [4]:

1. Yoga allows you to focus on your breathing. When a person is in an anxiety attack, breathing is short and superficial. This can aggravate a panic attack because this type of

Stress management techniques
Materials of International Practical Internet Conference "Challenges of Science" 
breathing causes weakness and a light-headed. The most important aspect of yoga is to focus on breathing. Practicing one's breathing through one's yoga practice is a useful skill that can be applied to other areas of life. If you feel anxious or stressed, do not forget to take deep breaths until you begin to feel more relaxed. Breathe walk and alternative nostril breathing could be an excellent example for this type of yoga $[5,6]$. Breathe walk is based on a Kundalini yoga technique, and involves making strong, purposeful strides in rhythm with breathing. Dr. Weil's colleague, Dr. Jim Nicolai, demonstrates various examples of breathe walk including the "stair" and "wave" patterns. Check out Dr. Jim Nicolai's video:

https://www.youtube.com/watch?v=TGkHVEnpVoY\&t=55s

2. Exercise releases endorphin. Like other forms of exercise, yoga can release endorphin (Look at figures - 1 and 2). Endorphins are brain neurotransmitters, which do improve mood, reduce the symptoms of depression, and at the same time relieve stress and anxiety. Endorphins are essentially an all-natural antidepressant. Additionally, the flexibility and strength of yoga can help prevent injuries and reduce the chronic pain.
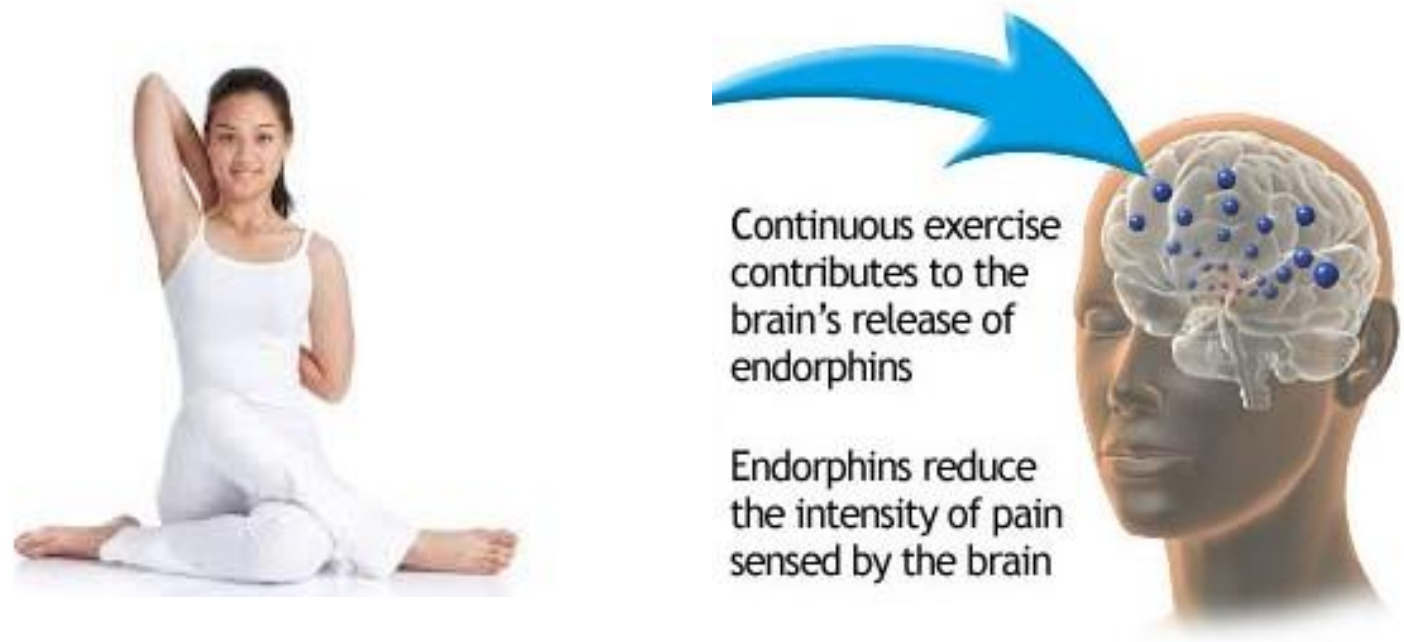

Figures -1 and 2. Yoga can release endorphin (Google engine search)

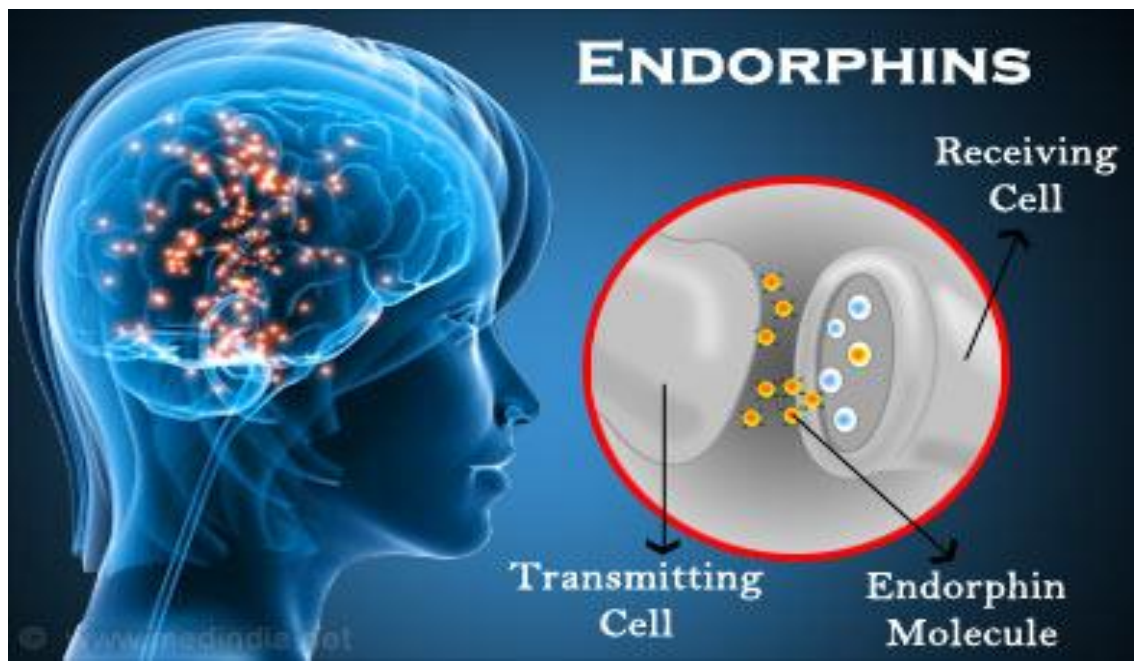

3. Yoga reduces muscle tension. When we have a feeling of anxiety or stress, we contract certain areas of our body without even realizing it. Stress or anxiety can lead to the pain and muscle tension in the back, head, neck, shoulders and to the other areas. Yoga helps to

Stress management techniques
Materials of International Practical Internet Conference "Challenges of Science" 
relieve muscle tension by strengthening, lengthening and relaxing sore muscles. Over time, yoga can also improve posture, which helps reduce muscle tension.

4. Yoga is difficult. Yoga is a challenge - even if you are a more experienced yogi, you will probably have some poses that are still difficult for you. Engaging in something that is difficult - and persevering even when it is difficult - will give you more confidence.

5. Yoga classes emphasize on the community and faith. When you feel anxiety, you may feel that no one understands you. This can lead to feelings of isolation and loneliness. Yoga classes are a way to meet new people and develop a sense of belonging. During resting postures, instructors offer ways for relaxing and be more present. In fact, the focus is on finding peace and strength in yourself. Having faith in something greater than yourself can be helpful when trying to cope with anxiety [4].

How often and how long should you practice yoga? In terms of integrating the qigong lessons into the regular school program, the biggest barrier appeared to be lack of time in the school day. One teacher observed: "The main problem was that I had to fit qigong into my lessons. And every day for 10 minutes - that is not easy. So if it were offered as an additional course, it would be easier and more relaxed." Another teacher mentioned problems with the school administration over the time needed for the program: "At the beginning we were expected to do it for 15 minutes, and then with level two it was supposed to be half an hour. This caused problems with the school directors. They said that 15 minutes were doable, but no more" [7]. Many yoga instructors agree that it can actually be more effective to practice frequently for shorter amounts of time (i.e. 15-30 min) than to have fewer longer yoga sessions. However, even if you can manage to do yoga once a week, the benefits of the practice will still be there [8].

Important for teachers: Teaching should be more focused on strengths rather than on weaknesses. 'Regenerative' management of stress: Recovery, enjoying, relaxing, breaks. Special techniques: Yoga, meditation, autogen training, Jacobson's progressive muscle relaxation. The Jacobson technique of progressive muscle relaxation is very easy and works well to come down from high-level stress. Focusing on good breathing also makes sense. 'Attention to breath meditation' has positive impacts on regulating aversive emotions, by down-regulating activation of amygdala (Doll et al., 2016, in Schachl) [9]. Meditation has also some positive effects (Ricard et al., 2015, in Schachl) [9], depending on the kind of meditation. Concentration meditation activates frontal brain areas, carefulness meditation areas in the parietal and temporal lobes and empathy meditation has impacts on regions between parietal and temporal lobes, and medial prefrontal cortex and insula [9].

Check out Jacobson's progressive muscle relaxation video in youtube: https://www.youtube.com/watch? $\mathrm{v}=\mathrm{ihO} 02 \mathrm{wUzgkc} \& \mathrm{t}=165 \mathrm{~s}$. It takes only 15 minutes and it is very convenient for both students and teachers to do it in the classroom before the start of the lesson every day. However, here are some types of yoga exercises which are doable in the classroom and outside as well. Twice a week it can be adjusted to the curriculum plan for students and it takes more time than 50 minutes.

\begin{tabular}{|l|l|c|}
\hline № & \multicolumn{1}{|c|}{ Type of yoga exercises } & Time \\
\hline 1 & $\begin{array}{l}\text { Breathe walk: While counting till 10 you should walk, then stop, look, listen } \\
\text { and feel. All these should be combined. Breathe walk is the science of } \\
\text { combining specific patterns of breathing synchronized with your walking steps } \\
\text { and enhanced with the art of directed, meditative attention. It changes our } \\
\text { mood. Experience has shown that you can conquer the most common forms of } \\
\text { anxiety and moderate depression with an appropriate program of Breathe walk. }\end{array}$ & \\
\hline
\end{tabular}

Stress management techniques
Materials of International Practical Internet Conference "Challenges of Science" 
Stress management techniques
Materials of International Practical Internet Conference "Challenges of Science" 


\begin{tabular}{|c|c|c|}
\hline & $\begin{array}{l}\text { and transcend false beliefs and preconceptions so that new, healthy information } \\
\text { can take root. Like other forms of meditation, it slows down your brain waves } \\
\text { to help you reduce stress, calm your mind, and become receptive to new, more } \\
\text { self-supporting beliefs. Brain Wave Vibration balances the frenzied mindset } \\
\text { associated with most modern lifestyles. } \\
\text { Brain Wave Vibration is a powerful, easy-to-follow brain fitness and holistic } \\
\text { healing method that helps you stimulate the flow of ki (chi, qi) to bring your } \\
\text { body and mind back into balance. Most ancient cultures recognize a universal } \\
\text { life force (energy) that exists in all things. Asian healing systems theorize that it } \\
\text { is the balanced flow of ki through certain pathways in the body (meridians) that } \\
\text { determines our health and well being. } \\
\text { At its core, the practice utilizes basic vibration exercises to stimulate the brain } \\
\text { stem, calm higher frequency brain wave activity, and circulate the body's ki. By } \\
\text { tapping into your body's inherent rhythm, you are able to release tension and } \\
\text { reach states of deep relaxation similar to that achieved through traditional } \\
\text { sitting meditation. It can be done anytime, anywhere by people of all abilities, } \\
\text { with or without music. Please visit the following link for more information: } \\
\text { http://www.brainwavevibration.com/learn/ }\end{array}$ & \\
\hline 4 & $\begin{array}{l}\text { Body tapping / slapping: EFT (Emotional Freedom Technique) tapping } \\
\text { therapy was first introduced in the 1990s by a man named Gary Craig, who } \\
\text { considered his approach to be an effective combination of mind-body medicine } \\
\text { and acupressure techniques. The underlying principle of EFT is that all } \\
\text { emotions and thoughts are forms of energy; this energy, whether positive or } \\
\text { negative, has very real physical manifestations that affect all functions of the } \\
\text { body. EFT was introduced around 1995, following another mind-body method } \\
\text { called Thought Field Therapy, or TFT. In the 1980s, TFT was developed by Dr. } \\
\text { Roger Callahan, a clinical psychologist, who found that it helped people } \\
\text { naturally manage symptoms of anxiety, phobias and physical problems related } \\
\text { to stress. } \\
\text { It May Help Reduce Stress, Depression and Anxiety. EFT has been proven to } \\
\text { help in the process of overcoming stress and related symptoms like trouble } \\
\text { sleeping, fatigue and panic. What do scientific studies say about the } \\
\text { effectiveness of EFT for reducing stress and anxiety? Over the past several } \\
\text { decades many studies have been conducted in an attempt to validate the } \\
\text { significance of EFT tapping and similar techniques and to determine how they } \\
\text { might work. Please visit the following link for more information: } \\
\text { https://draxe.com/emotional-freedom-technique-eft-tapping-therapy/ }\end{array}$ & 3 \\
\hline 5 & $\begin{array}{l}\text { Chi-Kung: One of the most important goals for teachers, parents and school } \\
\text { administrators is creating a healthy emotional environment for students. } \\
\text { A study published in the June } 2007 \text { issue of the Journal of Chinese Medicine } \\
\text { has found that including a particular type of qigong exercise program helped } \\
\text { calm and energize the students, as well as improving health and reducing } \\
\text { aggression. } \\
\text { Claudia Witt, MD, and colleagues from the Institute for Social Epidemiology, } \\
\text { Epidemiology and Health Economics at the University of Berlin, conducted a }\end{array}$ & 10 \\
\hline
\end{tabular}

Stress management techniques
Materials of International Practical Internet Conference "Challenges of Science" 


\begin{tabular}{|c|c|c|}
\hline & $\begin{array}{l}\text { study with } 140 \text { students among three elementary schools and one high school in } \\
\text { order to determine the effect of a six-month program of xianggong ("fragrant } \\
\text { qigong") movement instruction upon students' health and behavior. Teachers } \\
\text { were first instructed for eight weeks in the movements and then spent either } 15 \\
\text { or } 25 \text { minutes twice a week instructing students before or after regular lessons. } \\
\text { At the end of the six months, researchers conducted in-depth, semi-structured } \\
\text { interviews with the teachers. The teachers were first asked, "Have you noticed } \\
\text { any changes in your students during the qigong project?" They also were asked } \\
\text { if they were interested in continuing the qigong project. Please visit the } \\
\text { following link for more information: } \\
\text { http://natureshealing.info/qigong-improves-students-health/ }\end{array}$ & \\
\hline 6 & $\begin{array}{l}\text { The inner-smile: Based on Taoist Meditation practice, the inner smile } \\
\text { meditation is a simple yet profound meditation that is quite natural to many } \\
\text { people. It is centered on generating the benevolent qualities of a genuine smile } \\
\text { that we usually offer to others. The inner smile is an opportunity to offer a smile } \\
\text { to oneself. It can be done in a seated meditation session or in the midst of daily } \\
\text { life. The inner smile can also be integrated into hatha yoga practice and can be } \\
\text { particularly helpful during intense poses. Please visit the following link for } \\
\text { more information: } \\
\text { https://www.yogajournal.com/meditation/inner-smile-meditation } \\
\text { One of the most well-known of Taoist practices is the "Inner Smile", in which } \\
\text { we smile inwardly to each of the major organs of our body, activating within us } \\
\text { the energy of loving-kindness, and waking up the Five-Element associational } \\
\text { network. Here is how the inner smile meditation works, as taught by Master } \\
\text { Mantak Chia. Please visit the following link for more information: } \\
\text { http://www.laughteronlineuniversity.com/inner-smile-meditation/ }\end{array}$ & 5 \\
\hline 7 & $\begin{array}{l}\text { Mediation: What is meditation? Meditation is not about becoming a different } \\
\text { person, a new person, or even a better person. It is about training in awareness } \\
\text { and getting a healthy sense of perspective. You are not trying to turn off your } \\
\text { thoughts or feelings. You are learning to observe them without judgment. And } \\
\text { eventually, you may start to better understand them as well. Please visit the } \\
\text { following link for more information: } \\
\text { https://www.headspace.com/meditation-101/what-is-meditation } \\
\text { Meditation can be defined as a practice where an individual uses a technique, } \\
\text { such as focusing their mind on a particular object, thought or activity, to } \\
\text { achieve a mentally clear and emotionally calm state. Meditation has been } \\
\text { practiced since antiquity in numerous religious traditions and beliefs. Since the } \\
\text { 19th century, it has spread from its origins to other cultures where it is } \\
\text { commonly practiced in private and business life. } \\
\text { Meditation may be used with the aim of reducing stress, anxiety, depression, } \\
\text { and pain, and increasing peace, perception and wellbeing. Meditation is } \\
\text { under research to define its possible health (psychological, neurological, } \\
\text { and cardiovascular) and other effects. Please visit the following link for more } \\
\text { information: }\end{array}$ & 10 \\
\hline
\end{tabular}

Stress management techniques
Materials of International Practical Internet Conference "Challenges of Science" 


\begin{tabular}{|l|l|c|}
\hline & https://en.wikipedia.org/wiki/Meditation & \\
\hline 8 & $\begin{array}{l}\text { Total body relaxation: This is a slower method of self calming, meaning it will } \\
\text { take more time to complete. It will provide a deep all over sense of relaxation } \\
\text { and well being. Spend a few minutes in deep relaxation. Please visit the } \\
\text { following link for more information: } \\
\text { http://calmmindbody.com/mind/full-body-meditation-for-self-calming }\end{array}$ & $10+$ \\
\hline \multicolumn{1}{|c|}{ Total time in minutes } & $50+$ \\
\hline
\end{tabular}

In conclusion, stress has enormous consequences on our ability to learn, perform and to think. Especially during the education process, we have to do intensive work and sometimes really silly stressful events. In addition, we must teach our students to cope with anxiety and stress. This is helpful for our future careers, satisfying business and private life, and above all, for physical and mental health. Teachers should take care of those who are being educated by us and teach them various methods of stress management techniques like yoga, meditations; inspire them to read extra books and newspapers; help them to be engaged to sports, recreational activities etc. that can have therapeutic effects on students. The more students share their problems, feelings, interests, issues and desire with parents and teachers, the better opportunities they get to progress without any stress [2]. Yoga is one of the most effective ways to reduce anxiety and stress. It can help you focus on breathing, release endorphins, relieve muscle tension, gain confidence, and become part of a community.

\section{References}

1. Yerkes, Robert M., J. D. Dodson. The Relation of Strength of Stimulus to Rapidity of HabitFormation. Journal of comparative and neurological psychology 18 November 1908. P.459-482.

2. Gnawali Sh. D. Academic stress at schools: Causes and management. Published: December 08, 2017. https://thehimalayantimes.com/opinion/academic-stress-schools-causes-management/

3. Более 90 процентов казахстанцев испытывают постоянный стресс - Bolee 90 protsentov kazakhstantsev ispytyvayut postoyannyi stress. Published: 03/05/2018. https://www.nur.kz/1730140-bolee-90-procentov-kazahstancev-ispytyvaut-postoannyj-stress.html

4. 5 ways yoga lowers stress and anxiety. Published: 4/30/2018. http://www.samsarahathayoga.com/news/5-ways-yoga-lowers-stress-and-anxiety.html?lang=fr

5. http://www.kundaliniresearchinstitute.org/breathwalk/whatisbw/science.html

6. https://www.healthline.com/health/alternate-nostril-breathing\#takeaway

7. http://natureshealing.info/qigong-improves-students-health/

8. https://www.doyouyoga.com/how-often-should-you-practice-yoga/

9. Schachl H. Neuroscience: A Traditional and Innovative Approach to Education with Focus on Stress with Learning. Signum Temporis. 2016; 8 (1): p. 9 - 21

https://doi.org/10.1515/sigtem-2016-0012

Stress management techniques
Materials of International Practical Internet Conference "Challenges of Science" 